\title{
The Electric Current Effect on Electrochemical Deconsolidation of Spherical Fuel Elements
}

\author{
Xiaotong Chen, Zhenming Lu, Hongsheng Zhao, Bing Liu, Junguo Zhu, and Chunhe Tang
}

Institute of Nuclear and New Energy Technology, Collaborative Innovation Center of Advanced Nuclear Energy Technology, Tsinghua University, Beijing 100084, China

Correspondence should be addressed to Xiaotong Chen; chenxiaotong@tsinghua.edu.cn and Zhenming Lu; sunmoon@tsinghua.edu.cn

Received 30 December 2016; Revised 31 March 2017; Accepted 19 April 2017; Published 18 May 2017

Academic Editor: Robert Morris

Copyright (C) 2017 Xiaotong Chen et al. This is an open access article distributed under the Creative Commons Attribution License, which permits unrestricted use, distribution, and reproduction in any medium, provided the original work is properly cited.

For High-Temperature Gas-Cooled Reactor in China, fuel particles are bonded into spherical fuel elements by a carbonaceous matrix. For the study of fuel failure mechanism from individual fuel particles, an electrochemical deconsolidation apparatus was developed in this study to separate the particles from the carbonaceous matrix by disintegrating the matrix into fine graphite powder. The deconsolidated graphite powder and free particles were characterized by elemental analysis, X-ray photoelectron spectroscopy (XPS), X-ray diffraction (XRD), scanning electron microscopy (SEM), energy dispersive spectrometer (EDS), and ceramography. The results showed that the morphology, size distribution, and element content of deconsolidated graphite matrix and free particles were notably affected by electric current intensity. The electrochemical deconsolidation mechanism of spherical fuel element was also discussed.

\section{Introduction}

The fuel elements of High-Temperature Gas-Cooled Reactor (HTR) are spherical and have an overall diameter of $60 \mathrm{~mm}$. A $5 \mathrm{~mm}$ thick unfueled matrix graphite shell comprises the outer portion of the sphere. The central, fueled region of the fuel element is $50 \mathrm{~mm}$ in diameter and is composed of $0.92 \mathrm{~mm}$ diameter tristructural isotropic- (TRISO-) coated fuel particles that are overcoated and pressed into a $50 \mathrm{~mm}$ diameter sphere [1]. The graphite matrix covered more than $95 \%$ weight of the fuel element. To study the irradiation behaviors of the spent fuel element, coated particles need to be separated and sampled from the matrix graphite from the inside out for further inspections of fission products distribution [2]. Therefore, the structural integrity of coated particles and the complete separation of coated particles from matrix graphite are two key issues for exact measurements. Intact coated particles consisting of silicon carbide $(\mathrm{SiC})$ and outer/inner pyrolytic carbon (PyC) layers should be maintained, with graphite matrix and overcoating layers removed $[3,4]$. Most practical methods of disintegration of HTR fuel elements studied in the past made use of the fact that graphite forms so-called intercalation compounds with certain elements, accompanied by enlargement of the C-spacing of graphite lattice [5-7]. In this process graphite matrix is loosened to such an extent that it disintegrates into fine graphite powder to liberate the coated particles.

Electrochemical deconsolidation method is based on anodic oxidation of graphite in electrolytes including strong acids [8-10] and salt solution [11,12]. Under the concentration gradient and electrostatic potential gradient, anions would transport towards anodic graphite matrix, with insertion into the graphite layer to form the well-known graphite intercalation compounds. Since the compounds are not stable, they could decompose naturally in the presence of water, resulting in the destruction of the graphite matrix $[13,14]$. If the deconsolidation is conducted in strong acid, carbon oxidization caused by dissociated acid cations would also lead to the destruction of the graphite matrix. During the deconsolidation, the electric current is considered as one of main factors that affect the deconsolidation procedure. In this study, the electric current effect on the electrochemical deconsolidation of spherical fuel elements was investigated in $\mathrm{HNO}_{3}$ electrolyte. Unirradiated spherical graphite balls with 


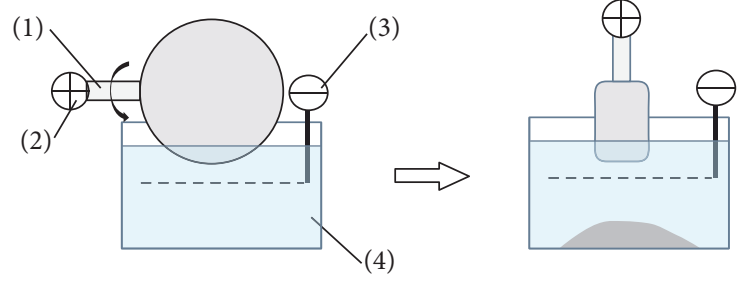

FIgURE 1: The electrochemical deconsolidation process.

$\mathrm{ZrO}_{2}$ kernels produced by the similar processing of $\mathrm{UO}_{2}$ fuel elements were used as the test samples in this work.

\section{Experimental}

The apparatus in this work contains electrolyzing cell, rotator (1), anode (2), Pt cathode (3), $\mathrm{HNO}_{3}$ electrolyte (4), and DC electrolytic power supply and control system (Figure 1). The sample sphere is connected to a direct current source as well as a gear motor using a motor rod linker. The motor rod linker is only inserted about $4 \mathrm{~mm}$ into the unfueled portion of the sphere to avoid particle damage as a result of the deconsolidation process. The deconsolidation process involves two steps. In the first part of the deconsolidation process, the sample sphere rotates $(1 \mathrm{rpm})$ with the outer circumference submerged in electrolyte solution, leaving a $2 \mathrm{~cm}$-cylinder in diameter at the end. In the second part of the process, the remaining cylinder is rotated by $90^{\circ}$ and lowered into the electrolyte in discrete steps. The tested electric currents in this work are $2 \mathrm{~A}(2.4 \mathrm{~V}), 7 \mathrm{~A}(6.4 \mathrm{~V}), 10 \mathrm{~A}(8.5 \mathrm{~V})$, and $13 \mathrm{~A}$ $(10.7 \mathrm{~V})$. Each step yields a sample of electrolyte solution, graphite matrix, and associated coated particles after a series of separation methods. Then unbonded particles are collected and packaged separately, providing a profile of fuel from the edge to the center of the sphere.

The deconsolidated powders were washed by SB-50 sonicator (Xinzhi, China) and dried by DHG-9030A (Yiheng, China). The samples were weighed by QUINTIX124-1CN (Sartorius, German). The X-ray diffraction (XRD) spectra of samples before and after deconsolidation were characterized by D8 X-ray diffractometer (Bruker, German); the X-ray photoelectron spectrometry (XPS) properties of samples were characterized by 250XI XPS instrument (Thermo, USA); the element contents of the samples were measured by Various ELIII element analysis instrument (Elementar, German); the scanning electron microscope (SEM) images were measured by S-3000N (Hitachi, Japan) equipped with energy dispersive spectrometer (EDS). The particle size was measured by Mastersizer 2000 laser particle size analyzer (Malvin, UK).

For elemental analysis, the deconsolidated samples were firstly sonicated by high purified water to remove $\mathrm{HNO}_{3}$ and filtrated by vacuum for times until the filter liquor $\mathrm{pH}$ reached above 6.0. Afterwards, the samples were dried at $120^{\circ} \mathrm{C}$ in a vacuum drying oven for $6 \mathrm{~h}$ to remove $\mathrm{H}_{2} \mathrm{O}$ with the weights measured. Then the samples were dried at $120^{\circ} \mathrm{C}$ for another $0.5 \mathrm{~h}$ and weighed. Once the weights differences before and after drying were smaller than $0.2 \mathrm{mg}, \mathrm{H}_{2} \mathrm{O}$ was thought to be

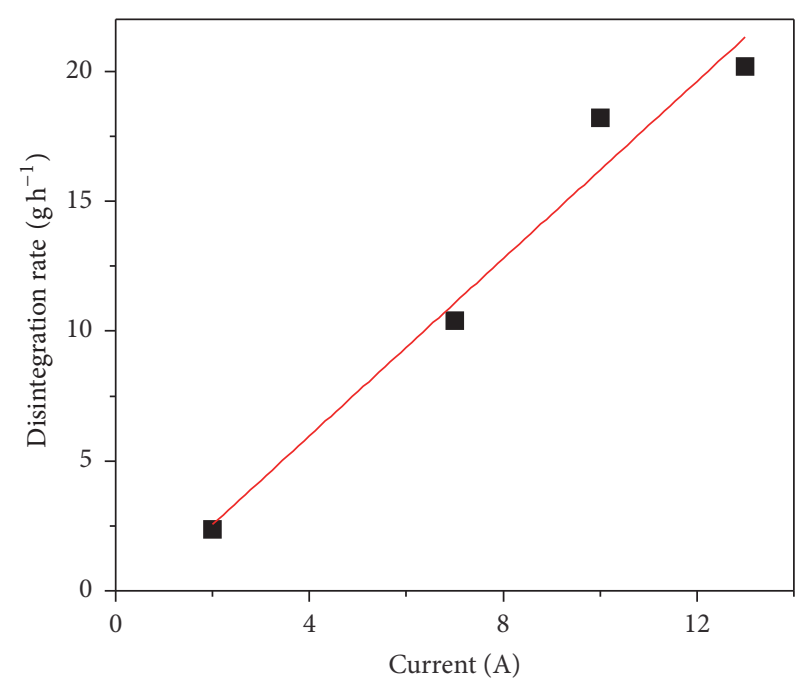

FIgURE 2: The electric current intensity effect on deconsolidation rate. $R^{2}=0.96$.

completely removed and the samples were sent for elemental analysis.

\section{Results and Discussion}

3.1. The Electric Current Effect on Deconsolidation Rate. The electric current effect on deconsolidation rate is shown in Figure 2. The deconsolidation rate is defined as the mass of disintegrated graphite fragments per hour. According to the results, a positive influence of current on the disintegration rate can be observed. It seems that a larger current leads to a faster disintegration rate. However, if the current is further increased to $20 \mathrm{~A}$, the disintegration rate will deviate from the linear relationship (not shown in the figure), which might be caused by competitive $\mathrm{H}_{2} \mathrm{O}$ electrolyzation.

\subsection{The Components of Graphite Matrix before and after Deconsolidation}

3.2.1. Elemental Analysis. If collected after deconsolidation, the graphite fragments gain an obvious weight of around $7-15 \%$ compared to those before deconsolidation. To examine the component of samples, elemental analysis was carried out for $\mathrm{C}, \mathrm{H}, \mathrm{N}$, and $\mathrm{O}$ contents (Table 1). Based on the mass balance, the difference between the overall mass and those of $\mathrm{C}, \mathrm{H}$, and $\mathrm{N}$ can be ascribed to the mass of $\mathrm{O}$. According to the elemental analysis results, $\mathrm{C}$ is still the main component of the fragments. The slight change of $\mathrm{N}$ content indicates the formation of graphite-nitrate compounds, which are probably intercalation compounds. The $\mathrm{O}$ increasing from graphite matrix to deconsolidated samples indicates that graphite matrix might be oxidized to some degree during the chemical deconsolidation, which results in the weight gain.

3.2.2. XPS Results. Since elemental analysis result is a mean value of the bulk of the sample, we further used XPS to characterize the sample surface with extensive functionalization. 
TABLE 1: The elemental analysis results before and after deconsolidation.

\begin{tabular}{|c|c|c|c|c|c|}
\hline Sample & N\% (mea.) & $\mathrm{C} \%$ (mea.) & $\mathrm{H} \%$ (mea.) & $\mathrm{O} \%$ (calc.) & $\mathrm{O} / \mathrm{C}$ \\
\hline Graphite matrix & 0.06 & 98.80 & 0.22 & 0.91 & 0.009 \\
\hline Deconsolidated by $2 \mathrm{~A}(2.4 \mathrm{~V})$ & 0.98 & 80.6 & 0.60 & 17.80 & 0.22 \\
\hline Deconsolidated by $7 \mathrm{~A}(6.2 \mathrm{~V})$ & 1.14 & 78.68 & 0.88 & 19.31 & 0.25 \\
\hline Deconsolidated by $10 \mathrm{~A}(8.5 \mathrm{~V})$ & 0.62 & 81.48 & 0.81 & 17.09 & 0.21 \\
\hline Deconsolidated by $13 \mathrm{~A}(10.7 \mathrm{~V})$ & 0.75 & 80.91 & 0.79 & 17.55 & 0.22 \\
\hline
\end{tabular}

TABLE 2: XPS fitting results.

\begin{tabular}{|c|c|c|c|c|}
\hline Sample & $284.6 \mathrm{eV}$ & $286.8 \mathrm{eV}$ & $289.0 \mathrm{eV}$ & $\mathrm{O} / \mathrm{C}$ \\
\hline Cont. & $\mathrm{C}-\mathrm{C}(\mathrm{H})$ & $\mathrm{C}-\mathrm{O}$ & $\mathrm{O}-\mathrm{C}=\mathrm{O}$ & \\
\hline Graphite matrix & $>99.8 \%$ & $<0.1 \%$ & $<0.1 \%$ & 0.04 \\
\hline Deconsolidated by $2 \mathrm{~A}(2.4 \mathrm{~V})$ & $65.3 \%$ & $29.8 \%$ & $4.8 \%$ & 0.39 \\
\hline Deconsolidated by $7 \mathrm{~A}(6.2 \mathrm{~V})$ & $73.2 \%$ & $16.2 \%$ & $10.5 \%$ & 0.24 \\
\hline Deconsolidated by $10 \mathrm{~A}(8.5 \mathrm{~V})$ & $45.6 \%$ & $37.5 \%$ & $16.9 \%$ & 0.59 \\
\hline Deconsolidated by $13 \mathrm{~A}(10.7 \mathrm{~V})$ & $60.9 \%$ & $33.8 \%$ & $5.2 \%$ & 0.56 \\
\hline
\end{tabular}

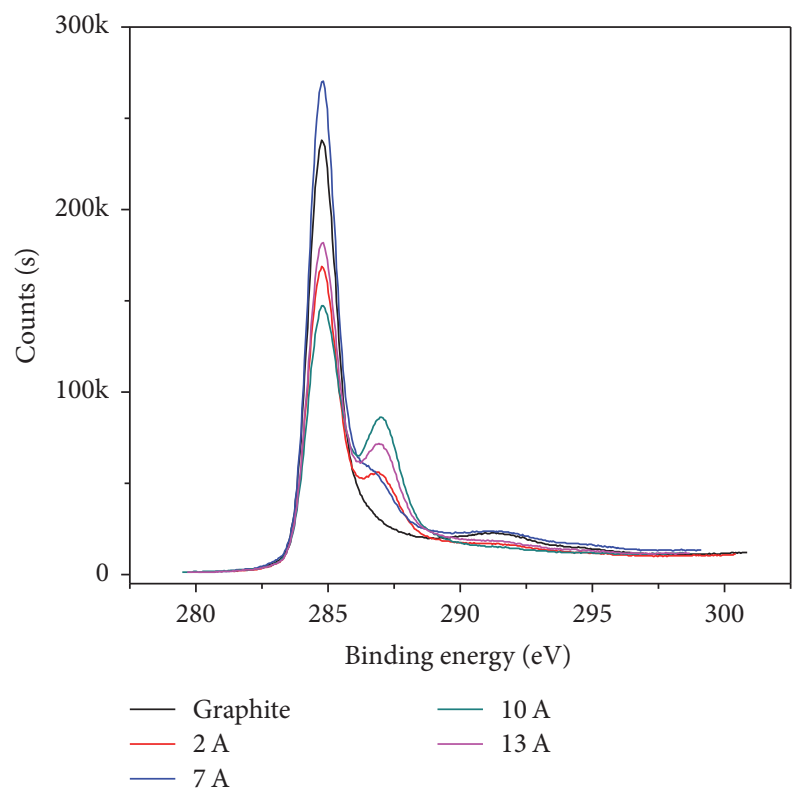

FIGURE 3: XPS results before and after deconsolidation.

XPS spectra for graphite before and after deconsolidation by different electric currents are shown in Figure 3. By means of deconvolution, one spectrum can be fit to three peaks at $284.6,286.8$, and $289.0 \mathrm{eV}$, separately [15], which can be assigned to $\mathrm{C}-\mathrm{C}(\mathrm{H}), \mathrm{C}-\mathrm{O}$, and $\mathrm{O}-\mathrm{C}=\mathrm{O}$ peaks (Table 2). According to XPS results, the graphite crystal accounted for more than $99.8 \%$ before electrochemical treatment, which decreased from $65.3 \%$ to $45.6 \%$ if the current intensity increased from $2 \mathrm{~A}$ to $10 \mathrm{~A}$. It is noted that the graphite proportion increased to $60.9 \%$ when the electric current further increased to $13 \mathrm{~A}$, which is probably due to the discounted oxidation effect with decreasing $\mathrm{O} / \mathrm{C}$ ratio at too rapid electrochemical rate (Table 2). Larger $\mathrm{O} / \mathrm{C}$ calculated from XPS results compared to those from elemental analysis results implies that more abundant graphite oxide was formed on the surface of graphite debris after deconsolidation.

3.2.3. XRD Results. The XRD results (Figure 4) also provide evidences about the formation of graphite oxide. The strong single peak at $26.5^{\circ}$ can be attributed to 002 diffraction peak of graphite crystal [16], indicating a high graphitization degree and an ordered arrangement of micrographite crystal layers. During the deconsolidation, the formation of covalent bond between oxygen and carbon atoms enhances the spacing in graphite crystal along $c$-axial, and the peak at around $12^{\circ}$ corresponds to the reflection of graphite oxides [17]. If we calculate the graphitization, $G$ value, according to (1), a declined graphitization can be observed for deconsolidated samples compared to the matrix (Table 3). Since the deconsolidated samples are inhomogeneous mixture of various carbon species, the graphitization is not dependent on current but lies in the range of $0.80-0.89$.

$$
\begin{aligned}
d_{002} & =\frac{\lambda}{(2 \sin \theta)} \\
G & =\frac{\left(0.3440-d_{002}\right)}{(0.3440-0.3354)}
\end{aligned}
$$

[18], where $\lambda$ is wavelength of the X-rays, $d_{002}$ is distance between 002 planes, and $\theta$ is the angle of incidence of the $\mathrm{X}$ ray beam.

3.3. The Current Intensity Effect on Particle Size of Graphite Matrix after Deconsolidation. If we look further into the current intensity effect on the particle size of graphite matrix after deconsolidation (Figure 5), the following can be found: as the current increased from $2 \mathrm{~A}$ to $10 \mathrm{~A}$, the particle size decreased from $365 \mathrm{~nm}$ to $148 \mathrm{~nm}$, which was correspondent to the previous study [7, 19]; as the current further increased to $13 \mathrm{~A}$, 
TABLE 3: $2 \theta$ and $G$ values of graphite powders produced by different deconsolidation currents intensities.

\begin{tabular}{lll}
\hline & $2 \theta\left(^{\circ}\right)$ & $G$ \\
\hline Graphite matrix & 26.54 & 0.95 \\
Deconsolidated by 2 A $(2.4 \mathrm{~V})$ & 26.46 & 0.83 \\
Deconsolidated by 7 A $(6.2 \mathrm{~V})$ & 26.48 & 0.86 \\
Deconsolidated by 10 A $(8.5 \mathrm{~V})$ & 26.50 & 0.89 \\
Deconsolidated by 13 A $(10.7 \mathrm{~V})$ & 26.44 & 0.80 \\
\hline
\end{tabular}

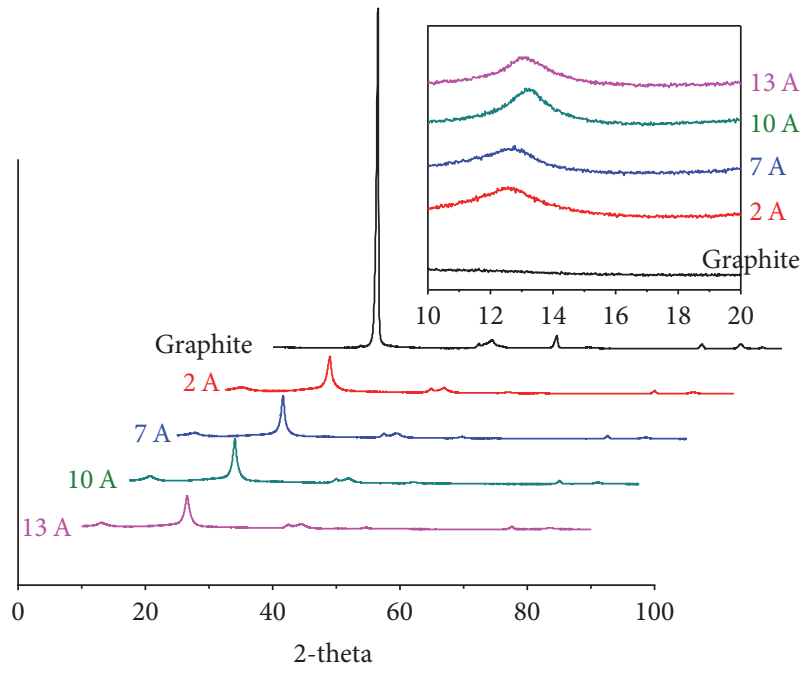

FIGURE 4: XRD results before and after deconsolidation.

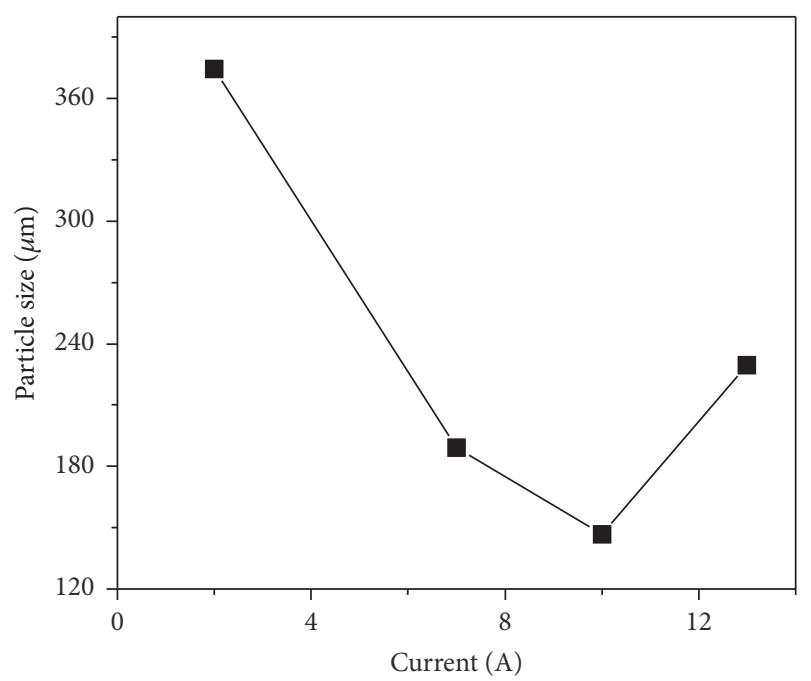

FIgURE 5: The current intensity effect on particle size after deconsolidation.

the particle size slightly increased to $240 \mathrm{~nm}$. These results indicate that when the electric current is relatively small, larger deconsolidated particles are more likely to be formed caused by more graphite oxidization inside the bulk. In this case, the permeation rate of $\mathrm{H}_{2} \mathrm{O}$ is faster than electrolysis rate, and the latter is a rate-control step. Inversely, when the electric current becomes large enough, fine particles are more likely to be formed caused by more graphite oxidation on the interface. On one hand, both electrolysis rates of graphite matrix and $\mathrm{H}_{2} \mathrm{O}$ become larger as current increases; on the other hand, the permeation rate of $\mathrm{H}_{2} \mathrm{O}$ into graphite matrix would become smaller with increasing $\mathrm{H}_{2} \mathrm{O}$ electrolysis rate. In this case, the permeation rate of $\mathrm{H}_{2} \mathrm{O}$ is slower than electrolysis rate of graphite matrix, and the former becomes the control step. Therefore, $10 \mathrm{~A}$ is a turning point where the rate-control step changes from electrolysis rate-control to permeation rate-control. According to these results, the electric current range from $7 \mathrm{~A}$ to $13 \mathrm{~A}$ would be recommended, because the large difference in particle sizes between graphite fragments and TRISO-particles benefits better separation of deconsolidated graphite powders and TRISO-particles. However, the OPyC layer may be degraded or broken at higher currents, which will be discussed in additional analysis in Section 3.4 .

The raw graphite matrix powder is composed of natural graphite, synthetic graphite, and resin binder in a certain proportion, which experience a series of high-temperature treatment to form graphite matrix [20]. The binder phenol resin is used to provide adhesion to mixture and helps to adhere the graphite matrix powder to TRISO-coated fuel particles during the overcoating process and will harden into a carbonaceous carbon during the subsequent carbonization process [21]. Compared to natural and synthetic graphite, the structure of carbonaceous graphite is not so ordered, so it is probably easier to be electrochemically oxidized. Also, micropore structure will be formed on the surface or in the bulk after manufacture processing due to powder compression and volatilization of light components in binder. According to SEM of the deconsolidated graphite sample (Figure 6), the graphite matrix surface is relatively smooth despite the porous structure, whereas the surface after deconsolidation becomes rough, displaying the shape of graphite raw materials. The electric current exerted little effect on the microstructure of the graphite. Since graphite microcrystalline is more ordered with higher reaction activation energy, it is reasonable to deduce that the carbonaceous carbon with turbostratic structure is easier to be broken in electrochemical process. During the electrolysis, the nitric acid electrolyte gradually infiltrated into the micropores of graphite matrix, and the electrochemical reaction would take place around micropore structure as well as on matrix surface. With much higher surface reaction capability due to large specific area of micropore structure, the expansion stress originated from 


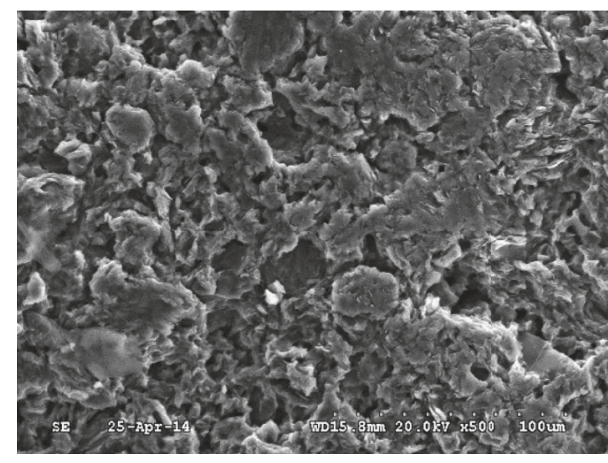

(a)

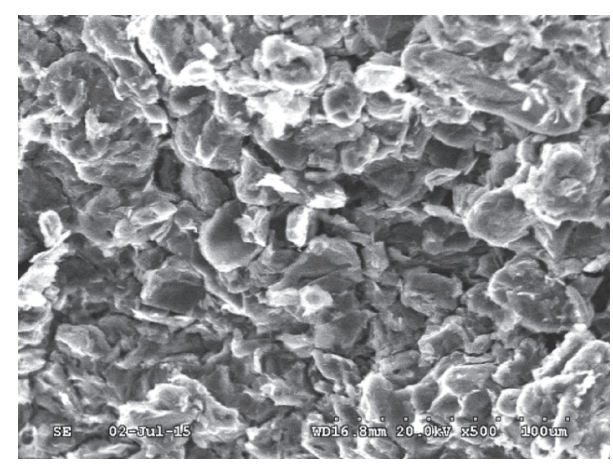

(b)

FIGURE 6: SEM images before (a) and after (b) deconsolidation.

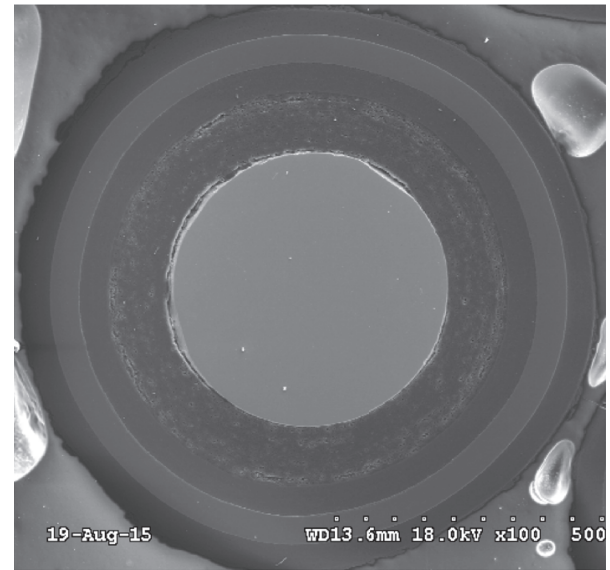

FIGURE 7: The ceramography of TRISO-particles deconsolidated by $7 \mathrm{~A}(6.2 \mathrm{~V})$.

inner surface of micropores widened the $c$-spacing of the layer lattice of carbonaceous carbon, which was thought to be one of the main driving forces of deconsolidation.

3.4. The Characterization of TRISO-Particles after Deconsolidation. During the deconsolidation, it is critical to maintain intact structure of obtained TRISO-particles for further analysis. According to ceramography (Figure 7) and EDS characterization of TRISO-particle surface after deconsolidation (Figure S1, Supplementary Material available online at https://doi.org/10.1155/2017/2126876), Si $(1.740 \mathrm{eV})$ was detected besides $\mathrm{C}(0.277 \mathrm{eV})$ and $\mathrm{O}(0.523 \mathrm{eV})$ if the samples are treated by large electric current like $10 \mathrm{~A}$ and $13 \mathrm{~A}$, indicating that the outer $\mathrm{PyC}$ layer was broken and $\mathrm{SiC}$ layer was exposed. Moreover, the detected Si peak at $13 \mathrm{~A}$ is stronger than that at $10 \mathrm{~A}$. Therefore, larger electric current might increase the breakage risk of PyC layer. Combining the above results for graphite fragments and TRISO-particles, the current of $7 \mathrm{~A}(6.2 \mathrm{~V})$ is preferred in this study.

\section{Conclusions}

In this work, the effect of different electric current intensities on deconsolidation of spherical fuel element was studied. It is shown that increased electric current improved deconsolidation rate. Particle size and components of deconsolidated graphite fragments were also related to the current intensity. According to the structure and surface analysis results, graphite oxide was produced after the deconsolidation, the content of which was also related to current intensities. The expansion stress originated from inner surface of micropores of carbonaceous carbon was thought to be one of the main driving forces of deconsolidation. Considering that larger electric current than 10 A would cause the breakage of OPyC layer and the exposure of $\mathrm{SiC}$ layer, the electric current of $7 \mathrm{~A}$ is preferred in this study.

\section{Disclosure}

Part of this work has been presented on a paper in Embedded Topical 2016 ANS Winter Meeting.

\section{Conflicts of Interest}

The authors declare that they have no conflicts of interest.

\section{Acknowledgments}

This work is supported by National Natural Science Foundation of China 21405092, the National S\&T Major Project (Grant no. ZX06901), Tsinghua University Initiative Scientific Research Program 2014z21025, and Nuclear Energy Development Project.

\section{References}

[1] C. Tang, Y. Tang, J. Zhu, Y. Zou, J. Li, and X. Ni, "Design and manufacture of the fuel element for the $10 \mathrm{MW}$ high temperature gas-cooled reactor," Nuclear Engineering and Design, vol. 218, article 91, 2002.

[2] C. Tang, Y. Tang, J. Zhu, X. Qiu, J. Li, and S. Xu, "Research and development of fuel element for Chinese $10 \mathrm{MW}$ high temperature gas-cooled reactor," Journal of Nuclear Science and Technology, vol. 37, article 802, 2000.

[3] G. D. Del Cul, B. B. Spencer, C. W. Forsberg et al., "Trisocoated fuel processing to support high-temperature gas-cooled 
reactors," Oak Ridge National Laboratory Report ORNL/TM2002/156, 2002.

[4] M. Masson, S. Grandjean, J. Lacquement, S. Bourg, J. M. Delauzun, and J. Lacombe, "Block-type HTGR spent fuel processing: CEA investigation program and initial results," Nuclear Engineering and Design, vol. 236, article 516, 2006.

[5] E. Merz, "Destruction of graphite matrix by metallic cesium. Application for processing pyrocarbon-coated nuclear fuels," Nukleonik, vol. 11, article 38, 1968.

[6] R. L. Gray and C. Calif, "Method for disposing of radioactive graphite and silicon carbide in graphite fuel elements," US, 5449505, 1995.

[7] E. Merz, "On the disintegration of graphite by the formation of electrolytic graphite intercalation compounds," Kerntechnik, vol. 12 article 341, 1970.

[8] H. Bildstein and K. Knotik, "The use of oxidizing acid mixtures to disintegrate fuel inserts for gas-cooled high temperature reactor," Kerntechnik, vol. 10 article 255, 1968.

[9] N. E. Sorokina, N. W. Maksimova, and V. V. Avdeev, "Anodic oxidation of graphite in $10-98 \% \mathrm{HNO}_{3}$," Inorganic Materials, vol. 37, article 360, 2001.

[10] V. V. Avdeev, O. A. Tverezovskaya, N. E. Sorokina et al., "Electrochemical study of the graphite- $\mathrm{HNO}_{3}$ system," Inorganic Materials, vol. 36, article 214, 2000.

[11] L. F. Tian, M. F. Wen, and J. Chen, "Analysis of electrochemical disintegration process of graphite matrix," Electrochimica Acta, vol. 56 article 985, 2010.

[12] L. Tian, M. Wen, and J. Chen, "Studies on disintegrating spherical fuel elements of high temperature gas-cooled reactor by an electrochemical method," Journal of Nuclear Materials, vol. 432 article 113, 2013.

[13] L. Tian, M. Wen, L. Li, and J. Chen, "Disintegration of graphite matrix from the simulative high temperature gas-cooled reactor fuel element by electrochemical method," Electrochimica Acta, vol. 54 article 7313, 2009.

[14] N. Sorokina E, L. Monyakina A, N. Maksimova W et al., "Potentials of graphite mitrate formation during spontaneous and electrochemical graphite intercalation," Inorganic Materials, vol. 38 article 482, 2002.

[15] S. Yumitori, "Correlation of C1s chemical state intensities with the O1s intensity in the XPS analysis of anodically oxidized glass-like carbon samples," Journal of Materials Science, vol. 35, article 139, 2000.

[16] F. Kang, T.-Y. Zhang, and Y. Leng, "Electrochemical behavior of graphite in electrolyte of suifuric and acetic acid," Carbon, vol. 35, article 1167, 1997.

[17] Z. D. Han, J. Q. Wang, and J. Chin, "Cesium-133 NMR studies of crown ether-cesium (1+) complexes in high dielectric amide solvents," Inorganic Chemistry, vol. 19, pp. 1366-1370, 2003.

[18] M. Inagaki and Y. F. Kang, Materials science and engineering of carbon: characterization, Butterworth-Heinemann, 2016.

[19] J. L. Fromm, "Recovery of valuable material from graphite bodies," US, 2903402, 1959.

[20] H. Zhao, T. Liang, J. Zhang, J. He, Y. Zou, and C. Tang, "Manufacture and characteristics of spherical fuel elements for the HTR-10," Nuclear Engineering and Design, vol. 236, article 643, 2006.

[21] X. W. Zhou, Z. M. Lu, J. Zhang et al., "Preparation of spherical fuel elements for HTR-PM in INET," Nuclear Engineering and Design, vol. 263, article 456, 2013. 


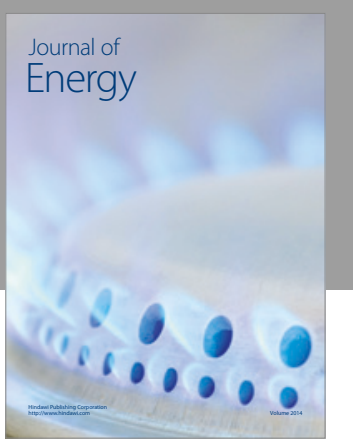

Journal of

Industrial Engineering
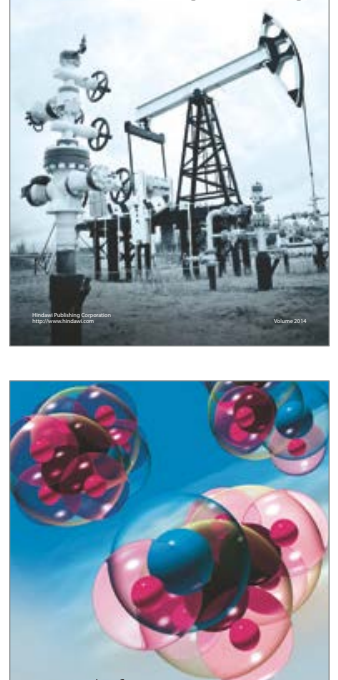

Fuels
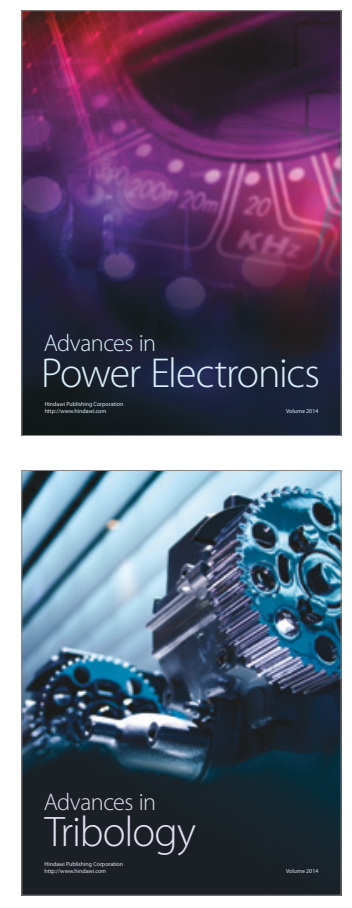
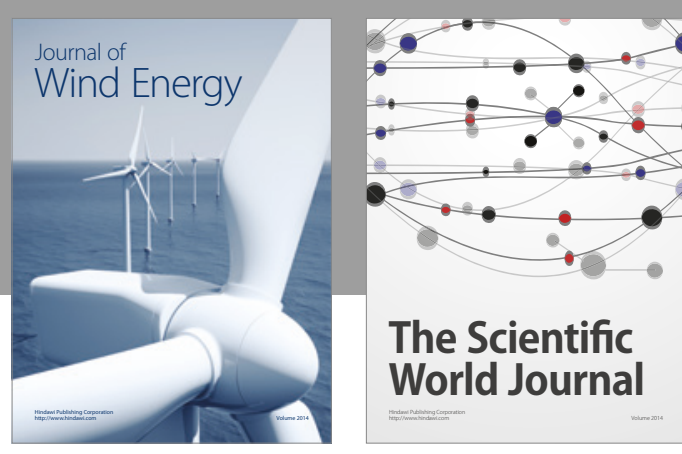

The Scientific World Journal
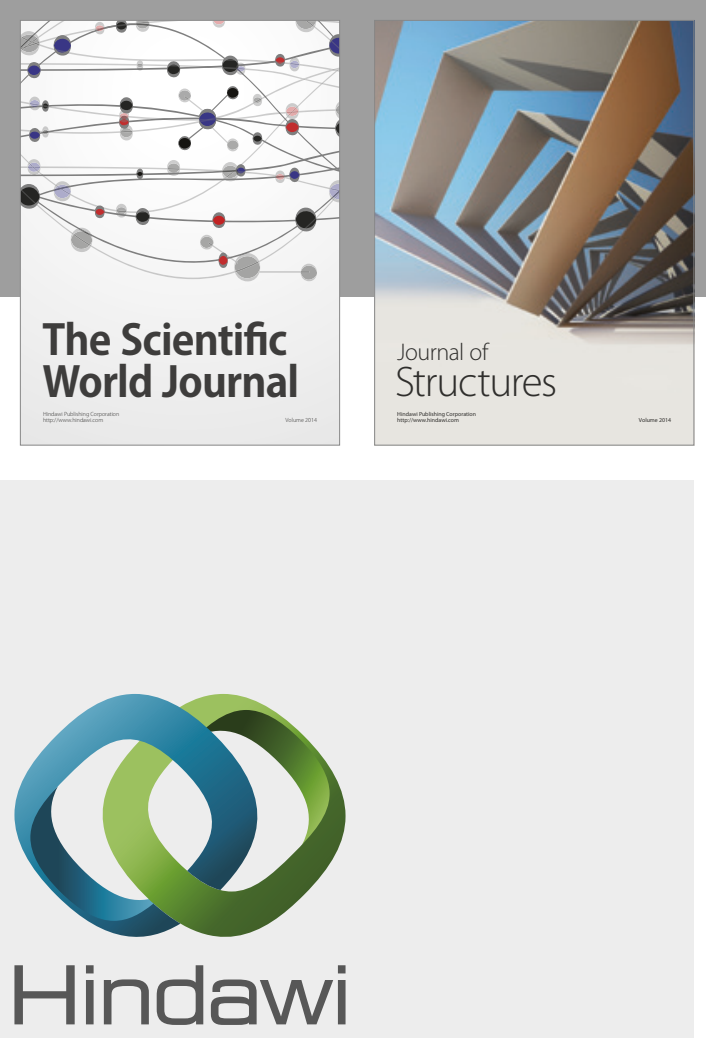

Submit your manuscripts at

https://www.hindawi.com
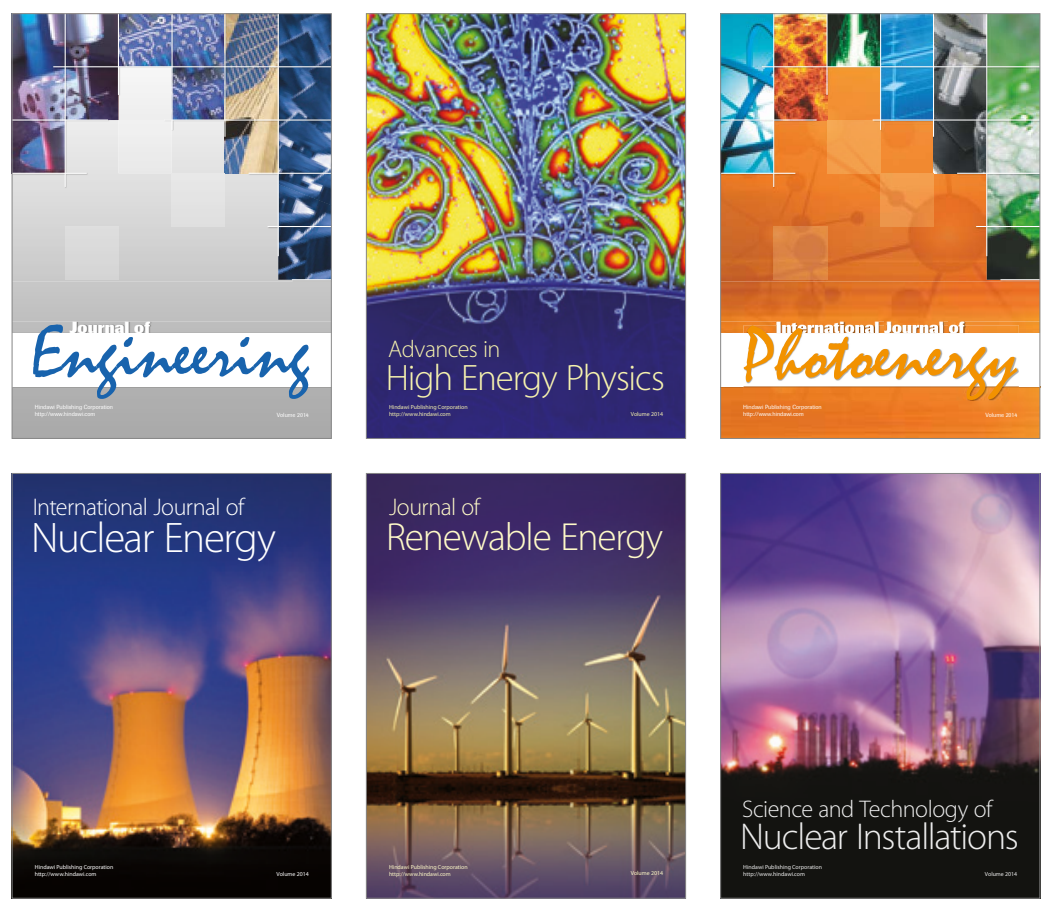

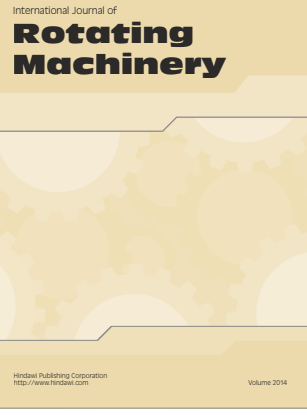

Journal of

Petroleum Engineering

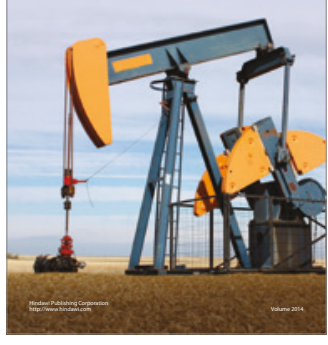

Journal of
Solar Energy
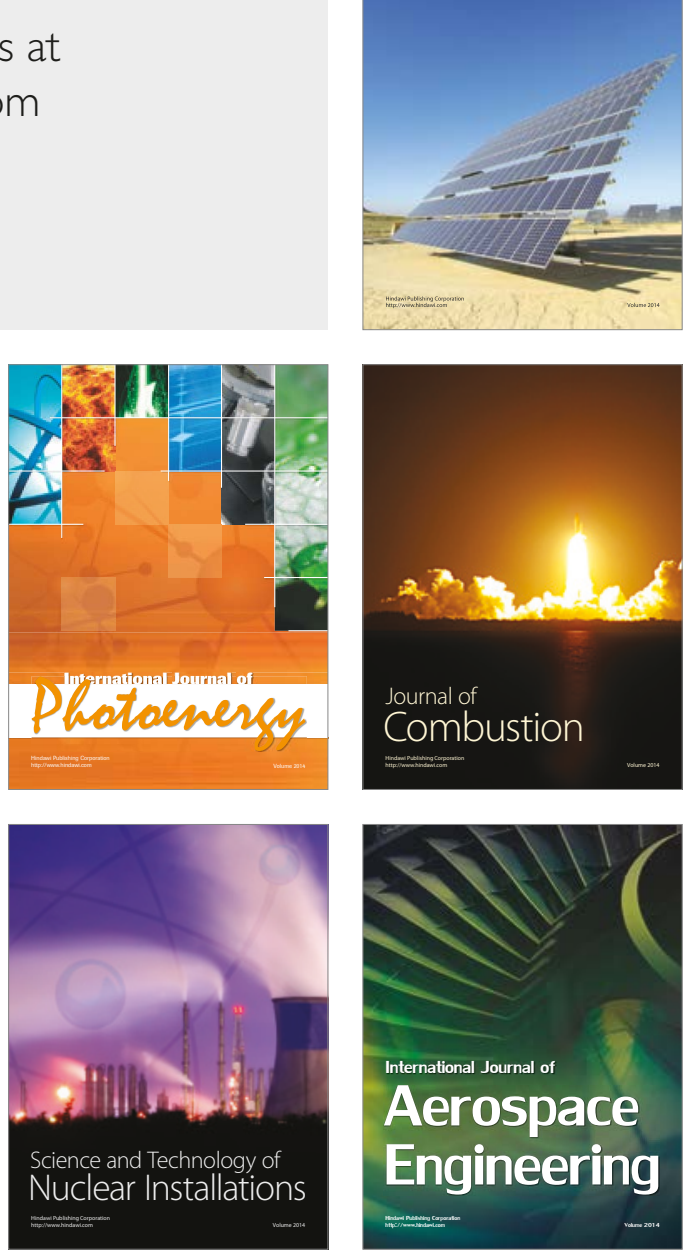